Ärztliche Erfahrung beschränkt sich nicht auf medizinisches Fachwissen. Sie entsteht auch aus den mehr oder minder alltäglichen, heiter, ärgerlich oder nachdenklich stimmenden Erlebnissen mit Patienten, Kollegen und Mitarbeitern. Senden Sie uns Ihre Geschichte an: Brigitte.Moreano@springer.com. Für jeden veröffentlichten Text erhalten Sie bis zu 100 Euro.

\section{Ein schwer greifbares Problem}

— Gegen 4 Uhr früh kam ein 20-jähriger Mann in die Notaufnahme. An der Anmeldung gab er nur zögerlich an, was ihn zu uns führte. Letztendlich klärte er uns dann doch auf: „Ich habe mir einen Vibrator rektal eingeführt und bekomme ihn nicht mehr raus." Natürlich mussten wir uns ein Grinsen verkneifen, um dem jungen Mann nicht noch mehr die Schamesröte ins Gesicht zu treiben.

Im Untersuchungsraum angekommen positionierten wir den Patienten in Steinschnittlage und führten vorsichtig einen Finger rektal ein. Das Gerät war so leider nicht greifbar, vibrierte jedoch noch! Selbst mit einer Zange ließ sich der Vibrator nicht greifen, so dass wir uns für eine endoskopische Bergung entschieden. Zur Lagebe-

stimmung fertigten wir noch eine Abdomenübersichtsaufnahme an.

Ich rief die zuständige Oberärztin an, welche (morgens um 4.30 Uhr) auch etwas ratlos war, wie dieses Gerät zu greifen sein solle. Sie machte sich jedoch auf den Weg in die Klinik. Zwischenzeitlich verabreichten wir dem Patienten noch ein Klysma, in der Hoffnung, dass das "Spielzeug" von alleine abgehe. Und tatsächlich: Beim Pressen auf der Toilette flutschte der Vibrator heraus! Nicht nur die Oberärztin war über diese spontane Lösung froh ...

Den Namen des zu informierenden Hausarztes hat der Patient übrigens zufällig vergessen.

Thomas Krause, ReutLingen -

\title{
Tiefschlaf am Tatort
}

— Einmal hatte ich eine Haftfähigkeitsuntersuchung bei einem jungen Pärchen im Polizeigewahrsam durchzuführen. Die 22-Jährige lag halb sitzend auf der Holzpritsche in der Zelle. Auf Ansprache öffnete sie zunächst gar nicht und nach einiger Zeit nur sehr verhangen die Augen. Ich fragte nach Name und Geburtsdatum, was nur unter mehrfacher Wiederholung mit viel Mühe und lallend in Erfahrung zu bringen war. Ich fragte die junge Frau, welche Drogen sie genommen habe, erhielt aber keine zuverlässige Antwort. Sie schlief unter meinen Fragen wieder ein.

Ihr Freund in der Nachbarzelle war auf Ansprache etwas schneller bei der Sache, konnte Namen und Geburtsdatum etwas zielgerichteter benennen, machte in Bezug auf die Frage nach Art und Dosis der Drogen aber auch nur spärliche Angaben. Angeblich habe er nur (das Substitutionsmedikament) Subutex eingenommen. Sobald ich eine Sprechpause einlegte, schlief er sofort wieder ein.

Die diensthabenden Polizisten erzählten mir, dass die beiden in einem Supermarkt Saft und Kekse gestohlen hätten und aufgrund ihres auffälligen Verhaltens natürlich sofort vom Detektiv gefasst worden seien. Schon beim Verhör durch den Detektiv seien sie eingeschlafen und so auch von der Polizei angetroffen worden.

Dr. Med. Rainer Hakimi, Stuttgart .

\section{Berufswunsch}

— Anlässlich eines Rentnerworkshops (Kaffeeklatsch) hatte ich kürzlich die Möglichkeit, mich in einem tiefschürfenden Gespräch mit einem Vertreter der jüngsten Generation auszutauschen. Auf meine Frage "Was willst Du einmal werden?" erwartete ich ein paar exotische Berufe wie etwa Astronaut, Pilot, Kapitän, Richter oder Arzt. Aber weit gefehlt! Die Antwort hat mich schlicht weg umgehauen:

„Rentner!" kam es wie aus der Pistole geschossen.

„Warum in aller Welt willst Du ausgerechnet Rentner werden?"

„Dann könnte ich endlich einmal schlafen so viel und solange ich wollte ohne den Fortbildungsstress in der Schule, auf Arbeit und das ständige Gemeckere!"

Den weiteren Dialog möchte ich mir ersparen. Der Rentner als Traumberuf! Da bekommt das Wort sterben gleich eine ganz andere Dimension, ist doch in dem Wort ein weiteres Wort versteckt: (st)erben! Da wäre doch "Aussitzen" auch noch ein Traumberuf!

Das Gespräch hat tatsächlich so stattgefunden!

DR. UDO FUCHS, HAMBURG •

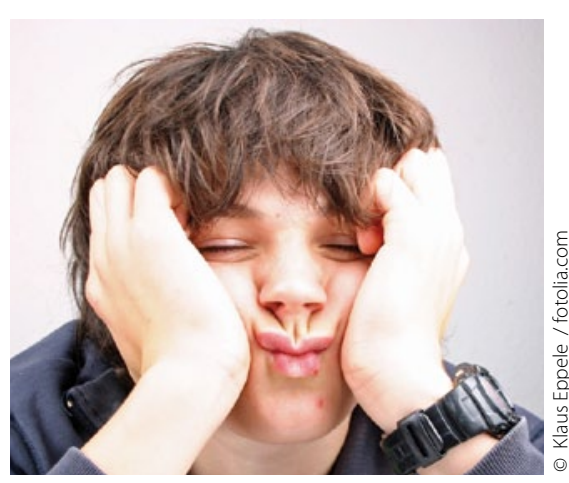

